\title{
Anthocyanin-rich Corn Extract
}

National Cancer Institute

\section{Source}

National Cancer Institute. Anthocyanin-rich Corn Extract. NCI Thesaurus. Code C117239.

A corn-based, water-soluble extract rich in the polyphenol anthocyanin, with potential antioxidant, anti-inflammatory and chemoprotective activities. Upon administration of the anthocyanin-rich corn extract, the anthocyanins scavenge reactive oxygen species (ROS), which protects healthy cells from radiation-induced oxidative stress and DNA damage. In addition, anthocyanins modulate the expression of various genes and proteins involved in inflammation, tumor cell proliferation, angiogenesis, tumor cell invasion and differentiation. This agent also chelates metals and induces the expression of enzymes involved in Phase II antioxidant and detoxification pathways, which may further protect cells against oxidative stress induced by toxins and carcinogens. 